\title{
Comparative Analysis of Central Asian Tourism Product from Point of View of Turkish Travelers: A Case of Kyrgyzstan, Kazakhstan, Tajikistan, Uzbekistan and Turkmenistan
}

\author{
Prof. Dr. Kemal Kantarcı (Alanya Alaaddin Keykubat University, Turkey) \\ Assoc. Prof. Dr. Murat Alper Basaran (Alanya Alaaddin Keykubat University, Turkey) \\ Ph. D. Candidate Paşa Mustafa Özyurt (Akdeniz University, Turkey)
}

\begin{abstract}
Central Asia (CA) region consist of five countries, Kazakhstan, Kyrgyzstan, Tajikistan, Turkmenistan and Uzbekistan, which is the core of Asian continent. Ancient Silk Road has played the critical role of connecting the East and West through the history and today. CA has a rich history, culture and nature conditions as pull factors for world tourism market. This region as a new destination is becoming more important in the international travel and tourism market. All five countries have been experiencing transition period and have been facing some domestic and international issues with respect to tourism perspective.

In this study, Turkish travelers for different motivations ranging from business to vacation visiting Central Asia are asked to evaluate the region based on some personal and expectation attributes. The investigation includes some fundamental factors such as key desires to travel to Central Asia or some mind-set not visiting there. For this purpose, approximately 200 responses are gathered from persons traveling there for different motivations including business, travel and so on. Multi Dimensional Scaling is run in order to display graphically the attributes on two dimensional graphs. This research is a pioneer work that sheds light on the future studies that will be conducted by both academicians and practitioners. Also, it reflects the Turkish travelers' expectations to $\mathrm{CA}$ region as a tourism destination.
\end{abstract}

The main findings can be summarized as the key factors leading people either to travel CA or not to travel there by gender, country and some other personal attributes.

\section{Introduction}

The Central Asia (CA) region has been unjustly neglected by global tourism and is home a wide variety of medieval historical monuments, as well as great natural beauties (Horak, 2014). This region has been at the crossroads of the Silk Road Route through the centuries that is perhaps the greatest and well known trade route in the history, which connected Europe and Asia. This amazing trade route formed the first bridge between east and west and increased trade among the ancient Empires of China, India, Persia, and Rome. The route, dating back to 200 B.C. was a channel for contact between people and cultures, inspiring the exchange of dialog, art, religion, ideas, and technology. Nowadays, the Silk Road has a chance to get its popularity back again. WTO (World Tourism Organization) initiated a Silk Road program in 1991 when the newly independent Central Asian countries came into the political arena (Develioglu and Kantarci, 2014; The European Union and Central Asia, 2009).

These CA countries occupying a territory of nearly 4 million $\mathrm{km}^{2}$ and having a total population of nearly 66 million consists of Kazakhstan having 2,7 million $\mathrm{km}^{2}$ with a population of 16.4 million, Kyrgyzstan having $199,951 \mathrm{~km}^{2}$ with a population of 5.5 million people, Turkmenistan having $488,100 \mathrm{~km}^{2}$ with a population of 5.2 million, Uzbekistan having $447,400 \mathrm{~km}^{2}$ with a population of 28.3 million, and Tajikistan having $143,100 \mathrm{~km}^{2}$ with a population 8.2 million people, respectively (UNDP, 2013). The region stretches from the Caspian Sea in the west to China in the east, and from Central Siberia in the North to Afghanistan, Iran and Pakistan in the South (Buyers, 2003; Kantarci, 2014).

CA countries located in the core of the Asia and contain large and untapped tourism resources to serve world tourism market. Although its share has been increasing very slowly, the region as a new destination has been gaining importance. After the collapse of the USSR in 1991, the CA countries have sharply developed tourism infrastructures and superstructures. In this short period despite the hard conditions and insufficient fund, lack of law and human resources, these countries achieved significant developments. To strive with lack of tourism and travel regulatory framework, tourism and travel business environment and infrastructure and undeveloped tourism and travel human resources can lead CA countries to understand tourism system clearly so that they might be better and deeper integrated with the world tourism market.

The five CA countries as a tourism destination have some similarities and differentiations. These five countries form the whole CA region as a tourism product, yet they are rivals to each other as a single tourist destination. These countries offer their unique tourism products on the base of the common culture and history of the region. In this point, having a unique tourism product might be determinative factor in order to have a comparative advantage. Each country has its own history, culture, traditions, geographical location and locals' involvement 
and acceptance of tourism. That's why the selection of a proper development tool is crucial. It is argued that public support for tourism development, resources and attractions, level of government involvement and the size of market are determinative factors for appropriate method of development model (Gartner, 1996; Kapiki and Tarikulov, 2014). Besides, comfort levels of host country accommodations, conditions of host country transportation infrastructure, natural and scenic beauty, quality of historical and cultural attractions, and perceptions of safety and security are also important pull factors (Uysal et al., 2008). However, to take benefit of these potential needs a long, complicated and expensive process. The success of this process depends on the availability of domestic and foreign capital and acceptable image (Uysal and Kantarci, 2006).

Tourism offers a wide range of benefits to countries. International tourist numbers reached 1,133 million and receipts reached US\$ 1.245 billion worldwide in 2014. In addition, tourism generated 1 in 11 jobs and $9 \%$ of total GDP worldwide in 2014 (UNWTO, 2015). It is known that CA countries have a great tourism potential. In order to strength its position in the market, CA countries needs to develop competitive strategies. Competitiveness has become the most critical field for the countries and the organizations in all areas including tourism. Table 1 shows inbound tourist numbers and tourism receipts of CA countries.

\begin{tabular}{clcccc}
\hline $\begin{array}{c}\text { Central Asian } \\
\text { Countries }\end{array}$ & Variables & $\mathbf{2 0 1 0}$ & $\mathbf{2 0 1 1}$ & $\mathbf{2 0 1 2}$ & $\mathbf{2 0 1 3}$ \\
Kazakhstan & Tourist arrivals (000) & 3,196 & 4,434 & 4,807 & 4,926 \\
& Tourism receipts (US\$ million) & 1,236 & 1,524 & 1,572 & 1,717 \\
& Tourist arrivals (000) & 975 & - & - & 1,969 \\
Uzbekistan & Tourism receipts (US\$ million) & - & - & - & - \\
Kyrgyzstan & Tourist arrivals (000) & 855 & 2,278 & 2,406 & 3,076 \\
& Tourism receipts (US\$ million) & 212 & 405 & 486 & 585 \\
Tajikistan* & Tourist arrivals (000) & - & - & - & - \\
& Tourism receipts (US\$ million) & - & - & - & - \\
Turkmenistan* & Tourist arrivals (000) & - & - & - & - \\
& Tourism receipts (US\$ million) & - & - & - & - \\
\hline
\end{tabular}

Table 1. Central Asian Countries Inbound Tourist Numbers and Receipts of 2010-13 Source: UNDATA, 2015

*: No Available Data

Porter (2004) stated that "competitive strategy is the search for a favorable competitive position in an industry, the fundamental arena in which competition occurs. Competitive strategy aims to establish a profitable and sustainable position against the forces that determine industry competition". According to Ritchie and Crouch (2003) competitiveness in tourism helps to tourism destinations to increase tourism expenditure, to attract more visitors while providing them quality tourist experience, enhancing quality of life of locals and visitors and preserving the environment in a profitable way. Economic coordination with neighboring countries can significantly strength competitiveness. In this point, tourism can help countries to regulate balance of payments and create new jobs, stimulate economy and encourage co-operations and collaborations among countries (Develioglu and Kantarci, 2014).

\section{CA Countries}

Kazakhstan has showed considerable progress in tourism infrastructure, accommodation sector, accessibility and good relation with neighbor countries and some mega tourism projects, promoting its image as an attractive, tourism friendly and dynamic Eurasian destination compared to neighboring countries in the region. Kazakhstan's competitive advantage is to have exotic culture, more familiar image, natural environment, more developed business environment, and sport and adventure tourism. Four core attractions of the country are on the UNESCO World Heritage Lists which are Mausoleum of Khoja Ahmed Yasawi, Petroglyphs within the Archaeological Landscape of Tamgaly, Silk Roads: the Routes Network of Chang'an-Tianshan Corridor, and Saryarka- Steppe and Lakes of Northern Kazakhstan (UNESCO, 2015). Especially nomad culture of Kazakhstan is known by the American and European tourism markets (Yessenova, 2014). The government considers tourism as one of the priority sectors for the economy. The strong side of the country is to have good basic workforce skills, low electricity cost, modern airport infrastructure and attractiveness for foreign direct investment. Weaknesses are the insufficient physical infrastructure, shortage of managerial skills and entrepreneurship, lack of advanced technical skills, safety and security and environmental sustainability (Porter, 2005; Baisakalova and Garkevenko, 2014).

Uzbekistan, one of the key countries on Silk Road, has a very rich cultural and natural resources such as mountains, steppes, lakes and religious attraction. The country has four cultural attractions in the UNESCO World Heritage List which are, Historic Center of Bukhara, Historic Center of Shakhrisyabz, Itchan Kala and Samarkand Crossroad of Cultures (UNESCO, 2015). Uzbekistan is considered to be a country with competitive 
advantage in the tourism sector, comparing with neighboring countries. Despite of having a great tourism potential, due to lack of proper promotion, insufficient funds and perceived negative image, Uzbekistan is not an important tourism destination in the world tourism arena. Lack of a unified tourism policy and strategy are urgent issues that stand in front of tourism development. Uzbek National Tourism Board, which is a public tourism organization, is the main ruler of tourism sector in the country (UNDP, 2007; Kapiki and Tarikulov, 2014).

Kyrgyzstan is a mountainous country with undiscovered natural beauties and unpolluted environment. The country has numerous lakes, mountains, valleys and glaciers that are very valuable recourses for tourism. The Issyk-Kul is the second largest alpine lake at high altitude and the deepest on the earth. Kyrgyzstan has two monumental structures listed in UNESCO World Heritage List which are Silk Roads: the Routes Network of Chang'an-Tianshan Corridor and Sulaiman-Too Sacred Mountain (Özcan, 2010; UNESCO, 2015). Tourism has many reasons to become a major alternative economy for the country and has been developing rapidly. Yet, there are some main obstacles that slowing down tourism development such as the soviet legacy, economic problems, political problems and legal problems. Tourism infrastructure, accommodation facilities, safety and security and corruption in bureaucracy affects the demand of direct foreign investments and tour operators to the country (Akçalı, 2014).

Turkmenistan has very rich natural resources and its economy largely depends on exports of energy recourses. The country has unique cultural and natural heritages such as Kunya-Urgench, Parthian Fortresses of Nisa and State Historical and Cultural Park Ancient Merv that are listed in UNESCO World Heritage List (UNESCO, 2015). The Awaza Tourist Zone, the biggest project in the history of country, aimed to attract foreign tourists to the country. The Karakum Desert occupies $80 \%$ of the whole country. Turkmenistan faces lack of infrastructure, transportation, accessibility to destinations, information and data. Visa regime still takes a lot of time and effort from demand side. Tourism education is relatively undeveloped. The difficulties and the corruption in bureaucratic procedures still exist. Turkmenistan's labor force generally lacks knowledge of standard (Doing Business in Turkmenistan, 2012).

Tajikistan is the poorest country in the region. It has two sites in UNESCO World Heritage List which are Proto-urban Site of Sarazm and Tajik National Park (Mountains of the Pamirs) (UNESCO, 2015). The country's tourism potential based on natural and historical resources. Tourism in Tajikistan has low impact on the national economy. Yet, the government devotes special attention to tourism and aiming to attract foreign investors that might create new jobs and revenues. Main challenges are lack of tourism infrastructure such as number and quality of accommodation facilities, transportation and promotion, safety and security conditions and negative image (Asia Policy Research, 2006).

\section{Methodology and Findings}

Questionnaires (2012-13) were directed to a number of 200 Turkish travelers familiar with the region in order to evaluate their experience and perceptions regarding the CA countries. The first part of statistical analysis summarizes some descriptive statistics. Despite of the fact the number of participants are mentioned to be 200, missing observation are observed. The frequencies based on some variables such as age, sex, and marital statuses are denoted through Tables 2-4 below. In Table 5, the frequencies of what types of means used are tabulated

The age of the travelers are tabulated in Table 2.

\begin{tabular}{|ll|}
\hline Statistics & Values \\
\hline Mean & 39.03 \\
Std. dev. & 12.15 \\
Min & 22 \\
Max & 69 \\
Missing & 28 \\
The number of respondents & 172 \\
\hline
\end{tabular}

Table 2: The Age of Travelers

The gender of travelers is tabulated in Table 3.

\begin{tabular}{|lll|}
\hline Gender & N & \% \\
\hline Male & 152 & 76 \\
Female & 48 & 24 \\
The number of respondents & 200 & 100 \\
\hline
\end{tabular}

Table 3: The Gender of Travelers 
The marital status of travelers are Tabulated in Table 4.

\begin{tabular}{|lll|}
\hline Marital Status & $\mathbf{N}$ & $\mathbf{\%}$ \\
\hline Married with kids & 93 & 46.5 \\
Single & 77 & 38.5 \\
Married & 26 & 13.0 \\
Missing & 4 & -- \\
The number of respondents & 196 & -- \\
\hline
\end{tabular}

Table 4: The Marital Status of Respondents

When traveling to CA, what types of organizations are used by travelers are tabulated in Table 5

\begin{tabular}{|lll|}
\hline Organization Type & $\mathbf{N}$ & $\mathbf{\%}$ \\
\hline Individual & 100 & 57.8 \\
Others & 39 & 22.5 \\
All-inclusive package & 18 & 10.4 \\
Flight and Hotel & 16 & 9.2 \\
Missing & 27 & -- \\
The number of respondents & 173 & -- \\
\hline
\end{tabular}

Table 5: The Types of Organizations Used By Travelers

Which country is the most preferred destination among travelers is determined that is denoted in Table 6.

\begin{tabular}{|lll|}
\hline CA Destinations & $\mathbf{N}$ & $\mathbf{\%}$ \\
\hline Kazakhstan & 76 & 38.0 \\
Whole region & 51 & 25.5 \\
Uzbekistan & 32 & 16.0 \\
Kyrgyzstan & 21 & 10.5 \\
Turkmenistan & 8 & 4.0 \\
Different combinations & 7 & 3.5 \\
Missing & 5 & -- \\
Responses & 195 & -- \\
\hline
\end{tabular}

Table 6: The Most Preferred Destination among Travelers

Some questions directed to travelers in order to express their perceptions regarding the region. The first is asked to expressing three words that pops up in their minds, its results are denoted in Table 7.

\begin{tabular}{|llll|}
\hline Rank & Words & N & \% \\
\hline 1st & History & 64 & 32 \\
2nd & Nature & 31 & 15 \\
3rd & Cultural & 10 & 5 \\
& Attractions & & \\
\hline
\end{tabular}

Table 7: The First Three Words Popping Up In Travelers' Mind Regarding CA

The second is asked to articulating three words travelers expect and feel about denoted in Table 8.

\begin{tabular}{|llll|}
\hline Rank & Words & N & \% \\
\hline 1st & Happy & 54 & 27 \\
2nd & Thrill & 20 & 10 \\
3rd & Sincere & 8 & 4 \\
\hline
\end{tabular}

Table 8: The First Three Feelings Popping Up In Travelers'Mind Regarding CA

The third is asked to articulating three cities that pop up in their minds of travelers when considering CA as destination. The cities and their frequencies are denoted in Table 9. 


\begin{tabular}{|llll|}
\hline Rank & Cities & N & \% \\
\hline 1st & Alma-Ata & 33 & 17 \\
2nd & Samarkand & 25 & 13 \\
3rd & Tashkent & 25 & 13 \\
\hline
\end{tabular}

Table 9: The Three Cities Popping Up In Travelers' Minds

The fourth is asked to expressing how they have been informed about CA denoted in Table 10.

\begin{tabular}{|llll|}
\hline Rank & Means of information & N & \% \\
\hline 1st & Friends and family members & 43 & 22 \\
2nd & Books and Movies & 36 & 18 \\
3rd & TV programs & 27 & 14 \\
\hline
\end{tabular}

Table 10: The Means of Information Obtained By Travelers

The fifth is asked to articulating similarities and dissimilarities of countries denoted in Table 11.

\begin{tabular}{|llllll|}
\hline Similar Countries & $\mathbf{N}$ & $\mathbf{\%}$ & Dissimilar Countries & $\mathbf{N}$ & $\mathbf{\%}$ \\
\hline Russia & 87 & 44 & Japan & 80 & 40 \\
Iran & 22 & 11 & Thailand & 17 & 9 \\
China & 16 & 8 & Iran & 16 & 4 \\
\hline
\end{tabular}

Table 11: Similarities and Dissimilarities of CA Countries with Other Asian Countries

The sixth is asked to describe the "best" three countries in Asia in terms of some attributes denoted in Table 12.

\begin{tabular}{|llll|}
\hline Features & 1st & 2nd & 3rd \\
\hline Shopping & China & Japan & Kyrgyzstan \\
Cultural/Historical Places & Uzbekistan & China & India \\
Nature & Kyrgyzstan & China & Russia \\
Climate & Kyrgyzstan & Uzbekistan & China, Japan, India \\
Accommodation & Japan & Russia & China \\
Service quality & Japan & Russia & Kazakhstan \\
Organizational capacity & Japan & Kyrgyzstan & Uzbekistan \\
Friendly attitude & Japan & Kyrgyzstan & Uzbekistan \\
Cost & Kyrgyzstan & China & Uzbekistan \\
Transportation to destination & Russia & Kyrgyzstan & Iran \\
Transportation within country & Japan & Russia & Kyrgyzstan \\
Security & Japan & China & Kazakhstan \\
Entertainment & Russia & Thailand & Ukraine \\
Purchasing power & Kyrgyzstan & china & Uzbekistan \\
Tourism information & Japan & Russia & China \\
Cleanliness & Japan & Russia & Kazakhstan \\
Environmental quality & Japan & Russia & China \\
\hline
\end{tabular}

Table 12: The "Best” Three Countries in Asia In Terms Of Some Attributes

The seventh is asked to articulating the "best" destination among countries in terms of some attributes denoted in Table 13. 


\begin{tabular}{|llllll|}
\hline \multicolumn{1}{|c}{ Features } & $\mathbf{1}^{\text {st }}$ & $\mathbf{2}^{\text {nd }}$ & $\mathbf{3}^{\text {rd }}$ & $\mathbf{4}^{\text {th }}$ & $\mathbf{5}^{\text {th }}$ \\
\hline Shopping & Kazakhstan & Kyrgyzstan & Uzbekistan & Turkmenistan & Tajikistan \\
Cultural/Historical Places & Uzbekistan & Kyrgyzstan & Kazakhstan & Turkmenistan & Tajikistan \\
Nature & Kyrgyzstan & Kazakhstan & Uzbekistan & Turkmenistan & Tajikistan \\
Climate & Kyrgyzstan & Uzbekistan & Kazakhstan & Turkmenistan & Tajikistan \\
Accommodation & Kazakhstan & Uzbekistan & Kyrgyzstan & Turkmenistan & Tajikistan \\
Service quality & Kazakhstan & Uzbekistan & Kyrgyzstan & Turkmenistan & Tajikistan \\
Organizational capacity & Kazakhstan & Uzbekistan & Kyrgyzstan & Turkmenistan & Tajikistan \\
Friendly attitude & Kyrgyzstan & Turkmenistan & Turkmenistan & Kazakhstan & Tajikistan \\
Cost & Kyrgyzstan & Uzbekistan & Turkmenistan & Kazakhstan & Tajikistan \\
Transportation to & Kazakhstan & Kyrgyzstan & Turkmenistan & Uzbekistan & Tajikistan \\
destination & & & & Turkmenistan & Tajikistan \\
Transportation within & Kazakhstan & Kyrgyzstan & Uzbekistan & Tuan \\
country & & & & Tajikistan \\
Security & Kazakhstan & Uzbekistan & Kyrgyzstan & Turkmenistan & Tajikistan \\
Entertainment & Kazakhstan & Kyrgyzstan & Uzbekistan & Turkmenistan & Turkmenista \\
Purchasing power & Kyrgyzstan & Uzbekistan & Kazakhstan & Tajikistan & Tajikistan \\
& & & & & Tajikistan \\
Tourism information & Kazakhstan & Uzbekistan & Kyrgyzstan & Turkmenistan & Tajikistan \\
Cleanliness & Kazakhstan & Uzbekistan & Turkmenistan & Kyrgyzstan \\
Environmental quality & Kazakhstan & Uzbekistan & Kyrgyzstan & Turkmenistan & Tuan \\
\hline
\end{tabular}

Table 13: The “Best” Destination among CA Countries In Terms Of Some Attributes

The second part of analysis uses Multi-Dimensional Scaling (MDS) in order to graphically display attributes, countries, some reasons to visit CA countries and some reasons not to visit CA countries. In MDS, the distances between attributes based on the count numbers, namely, frequencies are employed using SPSS 20 version so that the location of attributes are determined on a two dimensional graph for easy interpretation. The main objective of this analysis is to put similar attributes together by MDS. MDS is a multivariate statistical technique aiming at display attributes or observations on a two or three dimensional graph based on using distances among them. Its interpretation is dependent upon the similarities and dissimilarities of the observations. The closer distance between them, the more related observations are. One of the main advantages of it is to observe whole observations or attributes just shrinking dimension.

Before proceeding to those analysis, the profile of Turkish travelers in general will be revealed based on the data collected in this research. The main objective is to determine which attributes Turkish citizens looking for when traveling abroad in general. The graphical result generated by MDS is denoted in Figure 1.

Of twenty different attributes is observed that just three separate groups of attributes, which are different than Factor Analysis, are extracted. Therefore, similar attributes as a group are located at a particular region of the two dimensional graph saying that they are closely related based on the distance criteria.

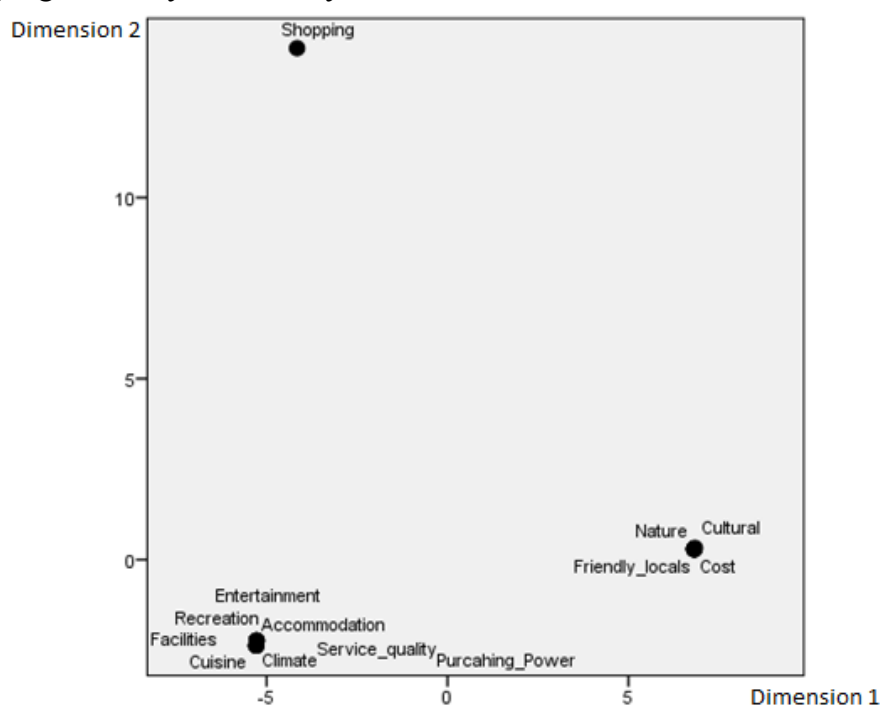

Figure 1. The Factors Determining Turkish Travelers Going Abroad 
When examining Figure 1, the first dissimilar attribute is shopping, the second group of attributes consisting of four features, namely, nature, cultural/historical, friendly locals and cost. The largest group of attributes consisting of several attributes, namely, entertainment, recreation, facilities, accommodation, cuisine, climate, purchasing power, and climate and service quality. It should be noted that not all attributes appear on the graph since the frequencies of some of responses are small. Whereas the second and third groups of attributes are equally likely important for travelers since both groups are located at bottom line on the two dimensional graph, the first factor, shopping, is seen differently than the others when Turkish travelers go abroad in general. Therefore, shopping is evaluated differently by Turkish travelers when going abroad. Its importance is relatively higher.

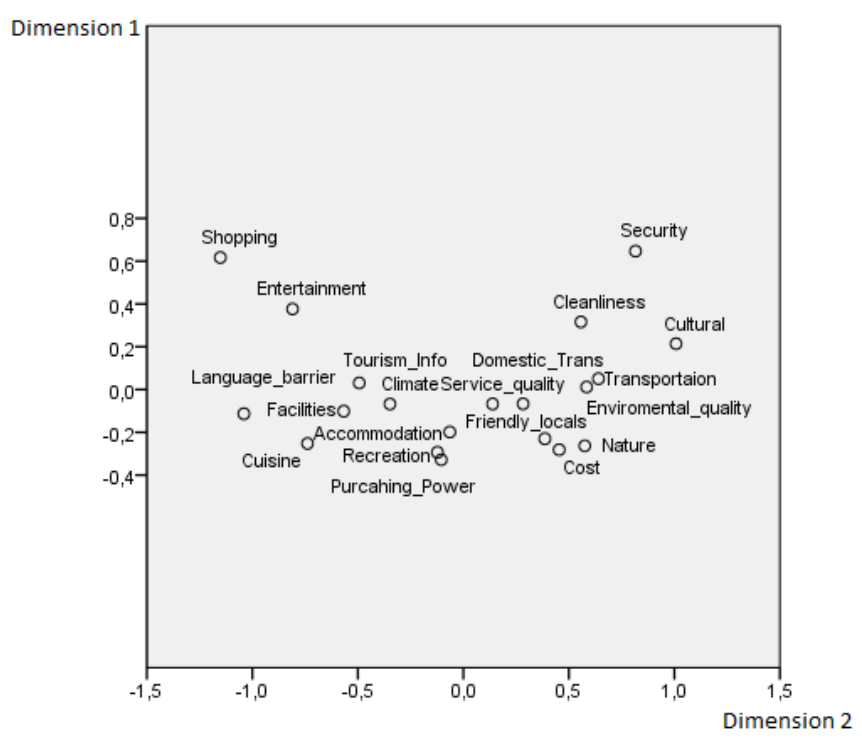

Figure 2. The Expectation of Turkish Travelers from CA Countries

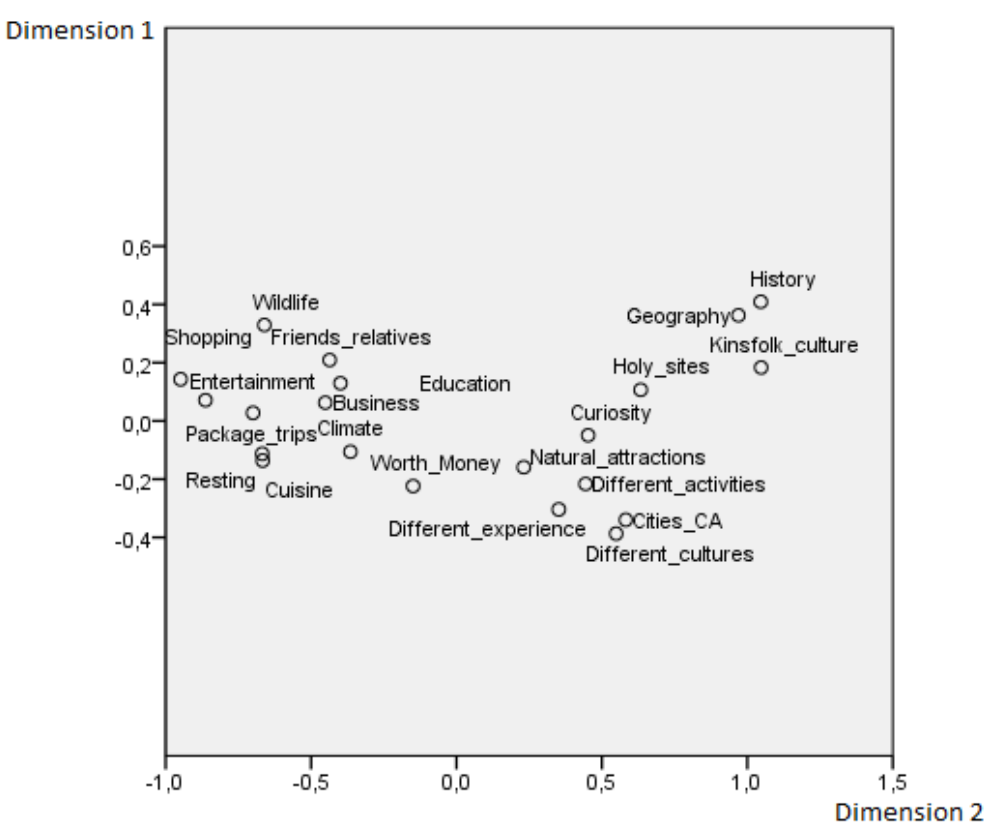

Figure 3. The Factors Affecting Your Trip to CA Countries

Figure 2 shows that when Turkish travelers visit CA countries, what types of tourism features they look for. The graph can be partitioned into two different sections including also an intersection area. The first section located at the left hand side of the graph tells that shopping, entertainment, tourism info, climates, accommodation, cuisine, recreation, facilities, purchasing power are a group of attributes. It is noted that while the shopping comes first, purchasing power comes last, which means that Turkish travelers again see shopping important when traveling to CA countries. On the other hand, purchasing power is seen the least significant attribute. The second section at the right hand side of the graph tells that security, cleanliness, cultural, transportation to destination, domestic transportation, environmental quality, nature and cost are group of attributes. It is noted that while security comes first, cost comes last, which means that Turkish travelers see 
security important when traveling CA countries. On the other hand, cost is seen the least significant attributes. The intersection area have quite few attributes such that climate, service quality and friendly locals saying that travelers are satisfied with those since they are significantly separated.

Figure 1 and Figure 2 providing us with comparison of the tourism features of Turkish travelers tells that shopping is very important for every type of destination. On the other hand, security, cleanliness and cultural attributes are seen important when traveling CA countries. Purchasing power and cost are two separate attributes believed to affecting different aspects of travelers. It is noted that while both are the least significant attributes for CA countries, they are not for other destinations, which means that Turkish travelers' purchasing power are strong and the cost of traveling those region is cheap.

When examining Figure 3 as the factors affecting travelers to visit CA countries, the two separate groups of attributes are seen. The first one located at the left hand side of the graph having attributes, namely, wild life, shopping, friends and relatives, entertainment, business, education, climate, package trips, resting, cuisine, worth money, and different experience. It should be noted that while wild life is seen as the most influential attribute, different experience is the least significant one. The second one located at the other side of the graph having attributes, namely, history, geography, kinsfolk's culture, holy cities, curiosity, natural attractions, different activities, cities in CA region and different culture. It should be noted that while history is seen the most influential attribute by Turkish travelers, the least one is the different culture.

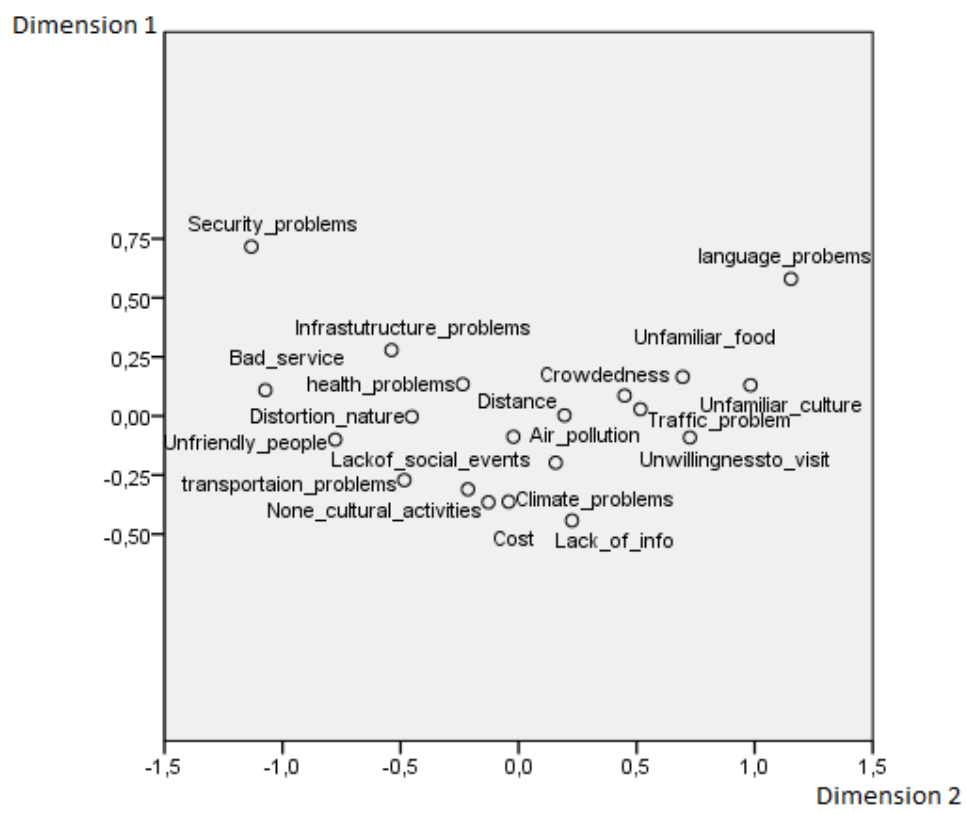

Figure 4. Factors Affecting Not to Visit CA Countries

When examining Figure 4 as the factors affecting travelers not to visit CA countries, the graph can be partitioned into two different sections including also an intersection area. The first section located at the left hand side of the graph has attributes, namely, security problems, infrastructure problems, bad service, health problems, and distortion of nature, unfriendly people, lack of social events, transportation problems, and lack of cultural events. It should be noted that while security problems and infrastructure problems are highly mentioned ones by travelers, lack of cultural events are the least mentioned ones. The right hand side of the graph has attributes, namely, language problems, unfamiliar foods, crowdedness, traffic problems, unwillingness to visit and lack of info. It should be noted that while language problems are mentioned most influential attribute as not to visit CA countries, the least influential attribute as not to visit CA region is lack of info. 


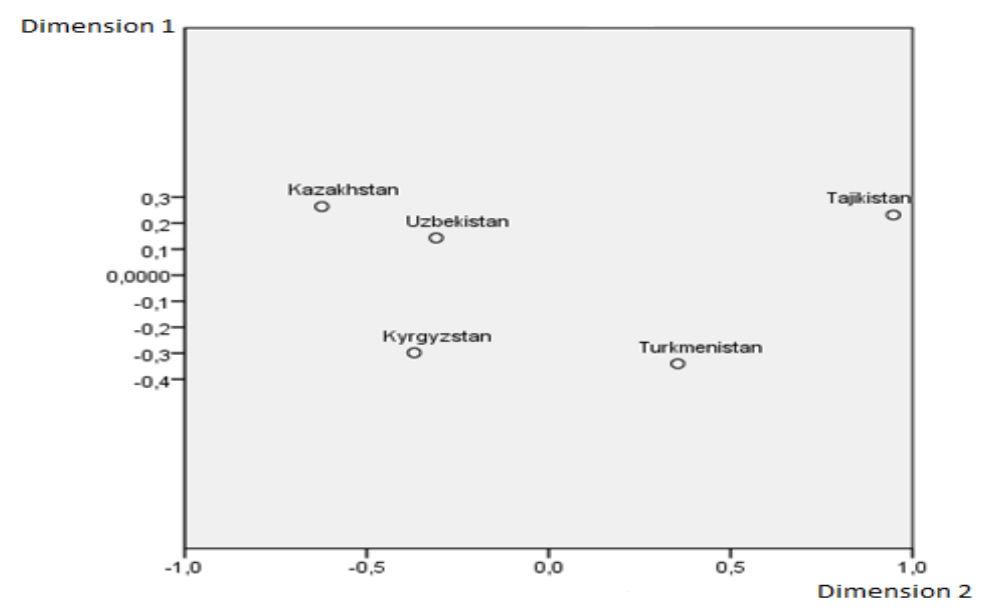

Figure 5. The Overall Evaluation of CA Countries in Terms of Tourism Destination

Examining Figure 5 in order to determine which country outperforms with respect to overall evaluation results in Kazakhstan. However, graphical display tells that Kazakhstan and Uzbekistan are similar countries. The second group of countries is Kyrgyzstan and Turkmenistan. Even though Kyrgyzstan and Turkmenistan are group of countries, Turkmenistan' position on the graph is between Kyrgyzstan and Tajikistan which means that similarities and dissimilarities of Turkmenistan are even. The most dissimilar one is Tajikistan which has the worst performance.

\section{Conclusion}

In this study, Turkish travelers' perceptions and expectations are mainly investigated when the tourism destination of CA region is chosen. Also, some comparison is provided based on the some tourism features Turkish travelers looking for when visiting abroad is partitioned into CA destination and others. Interesting findings are reached.

The way of organizing trip to CA is mainly conducted by travelers with almost 60 percent which means that either professional services such travel agencies and other package tours are poor or they are not preferred by traveler for some reasons. Kazakhstan is the most preferred destination among Turkish travelers. Interestingly, whole region as a destination comes after just Kazakhstan. History is the first word popping up in travelers' mind. Also, travelers believe to be happy and thrilled when thinking of CA a destination. The most attractive cities travelers want to visit are Alma-Ata, Saamrkand and Tashkent, respectively. The information sources used by travelers are friends and family members, books and movies and TV programs, respectively. While travelers find CA region very much similar to Russia, it is told that Japan is the most dissimilar county in Asia. When total of seventeen attributes are taken in to account, Kyrgyzstan (out of 4) and Uzbekistan (out of 1) are superior then other countries in Asia. The same comparison is made when CA is taken into account, Kazakhstan (out of 11), Kyrgyzstan (out of 5) and Uzbekistan (out of 1) are superior then other countries in CA region. According to Figure 5, Kazakhstan is the most competitive in terms of tourism country when it is compared to other countries in $\mathrm{CA}$ region.

On the other hand, the shopping attribute is the most influential one for both CA and other destinations. Turkish travelers have a special interest to CA region based on some very interesting attributes such as history, geography, kinsfolk's culture (root culture) and curiosity. Also, some issues needs to mentioned, which are security problems, lack of cleanliness, transportation problems and language barriers.

The region is vast and peoples of the region have common in history, culture and roots. Business, trade, education and other relations in the last few decades have increase travel density. However, it cannot be said that organized and mutual beneficial tourism has not been constructed. If doing so, both partners and region benefit from much.

Turkey has a potential market to CA region due to having common history, culture and root. CA region should reinvent their tourism products just targeted to Turkey's market. Hence, the number of visitors from Turkey should be increased which helps directly improve the economies of the region.

\section{References}

- Akçalı, P. 2014. Tourism in Kyrgyzstan, 259-286, in Tourism in Central Asia: Cultural Potential and Challenges, Kantarci, K., Uysal, M., and Magnini, V., (Eds), Apple Academic Press, Canada; Francis \& Taylor Group. 
- Asia Policy Research 2006. Tourism and Related Services Sector Background Brief October 2006, Retrieved June 23, 2015, from

- $\quad$ http://www.carecprogram.org/uploads/events/2006/CAREC-BDF/Tourism-Background-Brief.pdf

- Baisakalova, A., and Garkavenko, V. 2014. Competitiveness of Tourism Industry in Kazakhstan, 15-40, in Tourism in Central Asia: Cultural Potential and Challenges, Kantarci, K., Uysal, M., and Magnini, V., (Eds), Apple Academic Press, Canada; Francis \& Taylor Group.

- Buyers, L. M. 2003. Central Asia in Focus: Political and Economic Issues. Nova Publishers.

- Develioglu, K., \& Kantarci, K. 2014. Clustering Silk Road Countries Based On Competitiveness Factors In Tourism Industry, 201-232, in Tourism in Central Asia:Cultural Potential and Challenges, Kantarci, K., Uysal, M., and Magnini, V., (Eds), Apple Academic Press, Canada; Francis \& Taylor Group.

- Doing Business in Turkmenistan: 2012 Country Commercial Guide for U.S. Companies (2012). Retrieved May 14, 2015, from

http://photos.state.gov/libraries/turkmenistan/49351/pdf/Doing\%20Business\%20in\%20Turkmenistan\%2020 $12 \% 20$ CCG.pdf

- Gartner, W. C. 1996. Tourism Development: Principles, Processes, and Policies. Wiley.

- Horák, S. 2014. Visa Regimes And Regulatory Documents As An Obstacle For Tourism Development In Central Asia, 233-258, in Tourism in Central Asia:Cultural Potential and Challenges, Kantarci, K., Uysal, M., and Magnini, V., (Eds), Apple Academic Press, Canada; Francis \& Taylor Group.

- Kantarci, K., Uysal, M., \& Magnini, V. 2014. Exploring Tourism Potential in Central Asia, 1-14, in Tourism in Central Asia: Cultural Potential and Challenges, Kantarci, K., Uysal, M. \& Magnini, V. (Eds), Apple Academic Press, Canada; Francis \& Taylor Group.

- $\quad$ Kapiki, S. T., \& Tarikulov, M. 2014 . Development Prospects of Uzbekistan's Tourism and Hospitality Industry by Utilizing the EU Experience. In the Proceedings of the "International Conference on Tourism Milestones-Preparing forTomorrow", Sharjah, United Arab Emirates, DOI (Vol. 10, No. 2.1, pp. 4753 1845). Available at SSRN: http://ssrn.com/abstract=2546187

- Özcan, G. B. 2010. Building States and Markets: Enterprise Development in Central Asia. Palgrave Macmillan.

- $\quad$ Porter, M. E. 2004. Competitive Advantage. Free Press: New York

- Porter, M. E. 2005. Kazakhstan's Competitiveness: Roadmap Towards a Diversified Economy. Institute for Strategy and Competitiveness. Retrieved May 14, 2015, from

- $\quad$ http://www.hbs.edu/faculty/Publication\%20Files/Kazakhstan_Competitiveness 2005.01.26 35321255da68-4cb9-a97b-1cba5f2535f5.pdf.

- Ritchie, J. B., \& Crouch, G. I. 2003. The Competitive Destination: A Sustainable Tourism Perspective. Cabi.

- The European and Central Asia; The New Partnership in Action, 2009. Luxembourg.

- United Nation Data. 2015. Retrieved June 14, 2015, from

- http://data.un.org/Search.aspx?q=tourism

- United Nations Development Program. 2007. Policy Brief: Uzbekistan's Tourism Sector-an Unrealized Potential, No:2 (9), Tashkent 1-16.

- UNDP. (2013). World Population Prospects: The 2012 Revision. Retrieved from June 15, 2015, from

- $\quad$ http://esa.un.org/wpp/Documentation/pdf/WPP2012_\%20KEY\%20FINDINGS.pdf

- UNESCO. 2015. Retrieved June 20 2015, from http://whc.unesco.org/en

- UNWTO Tourism Highlights, Retrieved June 20 2015, from, http://dtxtq4w60xqpw.cloudfront.net/sites/all/files/pdf/unwto highlights14 en hr 0.pdf

- Uysal, M., Li, X., and Sirakaya Turk, E. 2008. Push-Pull Dynamics in Travel Decisions. Handbook of Hospitality Marketing Management, 412-439.

- Uysal, M., and Kantarci, K. 2006. An Integrative Approach to Image, Investment and Travel Conditions in Central Asia Countries (Kazakhstan, Kyrgyzstan, Uzbekistan, Turkmenistan). In Turk-Kazakh International Tourism Conference (pp. 138-146).

- Yessenova, S. 2014. Cinema as Branding, 173-200, in Tourism in Central Asia: Cultural Potential and Challenges, Kantarci, K., Uysal, M. and Magnini, V. (Eds), Apple Academic Press, Canada; Francis \& Taylor Group. 